\title{
CONFLITOS DO ESPAÇO URBANO RACIONALIZADO ${ }^{1,2}$
}

Grupo PET-Geografia ${ }^{3}$

\section{Resumo}

O tema deste trabalho é a racionalização do espaço urbano e a passagem compulsória de indivíduos que habitavam espaços marginalizados e agora habitam espaços inseridos dentro de um sistema legalizado ou, conforme Milton Santos, espaços luminosos. Partindo de uma apresentação histórica da evolução dos assentamentos urbanos no município de Porto Alegre/RS e uma discussão sobre a efetividade dos programas habitacionais, analisou-se as conseqüências sociais dessa transição ao mundo "legal" por parte daquelas pessoas que viviam em um espaço e em um tempo diferenciado. As questões de identidade e os conflitos gerados, não só pela inserção daqueles que antes viviam na informalidade, como também pela diversidade da procedência dos moradores, bem como a preocupação do poder público na inserção desses moradores ao mercado formal estão presentes no debate. Estas variáveis foram analisadas a partir do assentamento Princesa Isabel, localizado em uma área comercialmente valorizada da capital gaúcha, sendo que a sua construção foi decidia através do orçamento participativo. A metodologia utilizada consiste em um levantamento bibliográfico através do qual foram elaborados roteiros de entrevistas com integrantes da comunidade reassentada, assistentes sociais envolvidas em programas de auxilio aos moradores e o órgão público responsável, seguiu-se uma revisão dessas entrevistas e a redação final.

Palavras-Chaves: Assentamento Urbano, conflitos, (re)organização do Espaço Urbano.

\section{Introdução}

Atualmente a sociedade vive um estágio tecnificado, informatizado, sendo os meios de informação importantes agentes na intervenção e modificação do espaço. Essa relação intensa

\footnotetext{
${ }^{1}$ Pesquisa concluída pelo grupo do Programa de Educação Tutorial do curso de Geografia da Universidade Federal do Rio Grande do Sul (PET-GEA/UFRGS).

2 Artigo apresentado XVII SIC UFRGS.

${ }^{3}$ Ana Maria Sanches Dorneles Ferreira de Oliveira; Daniel Mallmann Vallerius; Éverton de Moraes Kozenieski; Fábio Guadagnin, Felipe Velho Azevedo Costa; Fernando Dreissig de Moraes; Fernando Weiss Xavier; Karen Aline Heberle; Neudy Alexandro Demichei, Rafael Zilio Fernandes; Renata Ferreira da Silveira; Rodrigo Bennett; Rosa Maria Vieira Medeiros; Tiago Bassani Rech; Stefan Szczesny Rout
} 
e veloz é perceptível principalmente no espaço urbano, espaço que reflete o processo industrial, bem como a exploração da força de trabalho e exclusão social.

De fato, é a partir dos anos 60 que se torna visível a intensificação da industrialização nacional, surgindo políticas econômicas voltadas a fortalecer os setores de ponta. Ao mesmo tempo em que temos a intensificação da industrialização, tem-se o surgimento do processo de urbanização, passando as cidades a serem o centro atrativo da sociedade em busca de uma melhora no padrão econômico e social.

Com a intensificação do processo de urbanização, conseqüência do novo modelo de acumulação colocado à sociedade, começa a ganhar importância à questão habitacional, sobretudo em função das periferias das cidades industriais.

Com a alteração da estrutura populacional, passando de aglomeração rural para uma aglomeração urbana, associada ao vertiginoso índice de natalidade, podemos afirmar, buscando auxílio em Martins, que

(...) fica patente, portanto, a necessidade e a preocupação do estado em promover uma política urbana em consonância com os propósitos da reprodução das relações de produção que se faziam presentes e hegemônicos, ou seja, impunham-se mudanças significativas na sociedade para que pudesse ser viabilizada tal urbanização, uma vez que o novo modo de acumulação não tem apenas a indústria como unidade central do "sistema" produtivo, mas faz da cidade, ela mesma, seu sentido e finalidade. (p. 167, 2001).

\section{Problemas Habitacionais}

Podemos seguramente dizer que um dos principais problemas das cidades é a habitação, onde principalmente, nas últimas décadas viu-se um aumento exacerbado de vilas (favelas) e cortiços; habitações precárias e em sua grande maioria irregulares; à margem da racionalidade urbana.

Um dos fatores imbricados no processo de precarização de moradia é o grande contingente de migrantes provindos do meio rural para os centros urbanos, motivo atrelado a falta de perspectivas quanto a aquisição de capital no meio rural e, a falsa idéia dos mesmos sobre as cidades serem o lugar ideal para uma melhora quanto as condições financeiras. Esse processo acaba por resultar em um "(...) desequilíbrio da estrutura urbana, uma vez que o inchaço urbano não acompanha a geração de novos empregos". (FREITAS, p. 20, 2003).

Como solução, a população excluída do modelo vigente, acaba alocando-se em vazios urbanos, podendo ser públicos ou particulares. Os vazios urbanos ocupados por esta população marginalizada encontram-se obviamente, em quase sua totalidade em locais 
afastados da área central da cidade; expandindo as cidades horizontalmente. Esse processo resulta na segregação urbana, em que Roberto Lobato Corrêa distingue-o em duas categorias; a auto segregação e a segregação imposta. A primeira remete-se a condição de determinada classe social escolher uma área para habitar e efetivar suas relações sociais. Enquanto que a segregação imposta está intimamente ligada às parcelas sociais desprovidas de condições econômicas e sociais são manipuladas e controladas pelas classes sociais detentoras do poder, poder este econômico e/ou político.

\section{Políticas Habitacionais}

A questão urbana é atualmente discutida por várias áreas do conhecimento, fato este relacionado a sua importância e, além disso, ao grau de complexidade em se discutir e resolver os problemas decorrentes de uma urbanização irracional. O país como um todo tem passado, principalmente na segunda metade do século $\mathrm{XX}$, por um processo de industrialização significativo, resultando no surgimento das cidades e, juntamente, seus espaços orgânicos e inorgânicos4.

Como procedimentos voltados a minimizar a problemática emergente, o Estado, busca a nível nacional, medidas administrativas que possuem por finalidade amenizar o problema habitacional, uma vez que, fazendo uso de uma linha de pensamento crítica, ao Estado não interessa resolver o problema habitacional enfrentado pelas classes excluídas (subalternas), mas "construir habitações para a legitimação do regime [vigente], para a barganha política e para o controle social, além de criar condições de acumulação do capital”. (PERUZZO, p. 36, 1984).

\section{Políticas Habitacionais de Porto Alegre}

No início do século XX o objetivo do Poder Público era o de tornar o centro uma área nobre, limpa e organizada. Com isso, a partir do primeiro quartil do século $\mathrm{XX}$ temos o surgimento dos subúrbios, uma vez que os pobres e trabalhadores de baixa renda são retirados do centro e levados para áreas periféricas.

A partir da década de 60, período sob o regime militar, é criado o Departamento Municipal de Habitação (Demhab), com a finalidade de executar projetos planejados e

\footnotetext{
${ }^{4}$ Sobre isto ler Milton Santos (2002).
} 
financiados pelo Banco Nacional da Habitação (BNH). Uma das principais obras do Demhab no período, foi a remoção de grande parte da população de núcleos irregulares para um terreno localizado na zona rural da cidade, o atual bairro Restinga, localizado na zona sul de Porto Alegre.

Em 1986 o BNH é extinto por motivos de desvirtuamento de sua política. Com o fechamento do BNH, a Caixa Econômica Federal passou a ser o órgão centralizador da política habitacional do Brasil.

\section{Política Urbana De Porto Alegre Pós Constituição De 1988}

Porto Alegre foi uma das cidades brasileiras que melhor aproveitou o "gancho" da Constituição Federal de 1988 para inovar em termos de Política Urbana e Habitacional. Para tanto, dois acontecimentos foram fundamentais. Em 1989, Porto Alegre elege uma Frente Popular encabeçada pelo Partido dos Trabalhadores com um slogan de campanha baseado na "Coragem de Mudar" e decidida a enfrentar os problemas da população de baixa renda. O novo governo adotou uma política de "inversão de prioridades" que tinha a questão da segurança da posse como um compromisso fundamental. Além disto, a Câmara de Vereadores promulgou, em 1990, a Lei Orgânica do Município, incluindo aí um capítulo intitulado Da Política e Reforma Urbanas, cujo conteúdo foi detalhadamente debatido por alguns vereadores comprometidos com as bandeiras da Reforma Urbana e por um Fórum de mais de 100 instituições que acompanhou ativa e propositivamente o processo constituinte municipal.

O Artigo 208 da Lei Orgânica foi contundente dispondo que o Município deveria assegurar o estabelecimento de diretrizes e normas relativas ao desenvolvimento urbano deverá assegurar, no parágrafo primeiro:

a urbanização, a regularização e a titulação das áreas faveladas e de baixa renda, sem remoção de moradores, exceto em situação de risco de vida ou à saúde, ou em caso de excedentes populacionais que não permitam condições dignas à existência, quando poderão ser transferidos, mediante prévia consulta às populações atingidas, para área próxima, em local onde o acesso a equipamentos e serviços não sofra prejuízo, no reassentamento, em relação à área ocupada originariamente.

A regularização fundiária é importante no caminho da garantia efetiva do Direito à cidade, já que nas últimas décadas se observa uma complexificação da segregação sócioespacial, em um fenômeno no qual os pobres passaram a ocupar também os interstícios da cidade formal e das regiões de alta renda, inclusive tendo em vista a busca de oportunidades de emprego e rendimentos, evidentemente mais abundantes nestas regiões da cidade. A 
possibilidade de regularizar as ocupações localizadas no tecido intra-urbano da cidade foi uma garantia à população pobre de que ela também terá "Direito ao Centro" e aos bens oferecidos por este mesmo centro.

\section{Especulação e Valorização do Espaço Urbano}

Decorrente de um crescimento urbano acelerado e de uma expansão horizontal das cidades, a exclusão social e a segregação sócio-espacial constituem um retrato da realidade e trazem consigo um número muito grande de problemas provenientes da preservação do sistema econômico hegemônico e da estrutura de classes vigentes.

A segregação residencial resulta de vários fatores, passando da pobreza à influência do estado no estabelecimento das disparidades sociais e de infra-estruturas, não esquecendo também dos agentes econômicos dominantes do mercado. Não só a exclusão social e a segregação sócio-espacial são frutos dessa combinação fatores, outros problemas como a degradação ambiental e a destruição de patrimônios culturais aparecem como o ônus desse “desenvolvimento". Desse modo, como lembra SOUZA,

Está-se diante, portanto, de mais que um simples agravamento da segregação residencial, muito embora esta se agrave à medida que a fragmentação avança. (...) A fragmentação do tecido sociopolítico-espacial é, também, muito mais que, meramente, um aumento das disparidades sócias: assiste-se (...), a um processo no qual a cidade, no ponto de vista sociopolítico, de fato se vai fragmentando, com conseqüências socioculturais, sociopolíticas e psicossociais. (2003, p. 90-91)

Segundo Santos (1990), atualmente milhares de pessoas somente têm acesso à moradia por processos informais e, freqüentemente ilegais. Esse tipo de ocupação do solo urbano se dá no momento em que a cidade expande os seus limites, deixando, porém, no seu interior, quantidade de terrenos vazios, segregando os moradores de acordo com sua estratificação social.

O quê fazer para regularizar essa situação? Quais são os instrumentos e as estratégias usadas pelo poder público e por aqueles que tem o interesse na manutenção da situação atual? Essas são questões habitualmente levantadas e que inúmeras vezes recebem respostas contundentes, mas que ficam apenas no campo teórico. Uma vez que a eficiência da aplicação desses instrumentos vai de encontro à manutenção da hegemonia doas agentes modeladores do espaço, pois essas melhorias devem se dar por parte do estado, sendo que o mesmo reserva 
pouco espaço para a participação da população na elaboração de projetos que visem suprir as necessidades da mesma.

Dentro desse contexto, a regularização fundiária pode ser entendida como um processo que visa promover a melhoria das condições ambientais e de moradia de um espaço de terras ocupado sem o controle urbanístico do poder público, integrando-o ao tecido urbano (BONIN. 1993, p. 337). No que tange às dimensões dos programas de regularização fundiária, os programas devem ser integrados seguindo aspectos jurídicos, sociais, ambientais e urbanísticos, a fim de promover a sustentabilidade das áreas regularizadas. Os programas de regularização devem objetivar a integração dos assentamentos informais ao conjunto da cidade.

Muitas outras questões são de suma importância ao poder público, uma vez que regularizar uma área carrega consigo o ônus do aumento da demanda por serviços de infraestrutura urbana, pois no processo de regularização, trechos de ruas (e as redes contidas nela) antes servidos informalmente, passam a ser incluídos nos cadastros oficiais dos sistemas públicos, exigindo, normalmente consideráveis investimentos inicias para a sua complementação ou adaptação às características técnicas do sistema. (BONIN, 1993, p. 338). Em contrapartida, a regularização fundiária impõe aos inúmeros ocupantes informais a necessidade de se incorporar ao sistema tributário, que antes sem pagarem impostos desfrutavam e demandavam os serviços públicos.

$\mathrm{O}$ instrumento mais importante de regularização fundiária, e que se faz presente no nosso estudo de caso, é a construção do direito real de uso, a fim de legalizar a posse de ocupantes de terrenos públicos. Introduzida mediante a aprovação do Estatuto da cidade, a concessão de uso especial para fins de moradia pode ser entendida conceitualmente, segundo ALFONSIN, como,

Um direito subjetivo garantido, segundo a regulação trazida pelo Estatuto da Cidade e seguida pela Medida Provisória, aos ocupantes de áreas públicas que até a data de 30 de junho de 2001 tenham já cinco anos de posse sobre terreno urbano de até $250 \mathrm{~m}^{2}$ e o utilizem para fins de moradia sem serem proprietários de outro imóvel urbano ou rural. Trata-se de um direito real, ou seja, um direito oponível a terceiros e não apenas ao concedente, que terá por título um contrato entre o Poder Público e o ocupante da área pública ou ainda uma sentença judicial. (2003, p. 98)

Vale lembrar que o que se concede ao cidadão por hora "legalizado" não é a propriedade do bem e sim a concessão de uso da propriedade. Ou seja, com a aplicação do direito real de uso não chega a se dar a transferência da propriedade, muito embora os ocupantes recebam garantias e vejam a sua situação ser regularizada (SOUZA, 2003, p. 295). 
Em uma realidade onde a urbanização se associa a inúmeros processos que degradam o modo de vida da população mais necessitada, através de processos de favelização e pereferização, entre outros, é necessário melhorar a qualidade de vida daqueles que tem acesso à moradia de forma irregular. Regularizar fundiariamente e dotar de infra-estrutura favelas e loteamentos irregulares são coisas essenciais para resgatar a dignidade e a autoestima dos pobres urbanos (SOUZA, 2004, p. 294).

A renovação das práticas de gestão das políticas urbanas vislumbra uma melhora nas condições de vida das populações mais necessitadas que sofram, ou sofreram um processo de segregação sócio-espacial induzido. A proteção contra o despejo, à possibilidade de acesso ao crédito formal, o direito a cidadania, entre outros, são produto desse processo de regularização. Idealmente, esses programas devem ser combinados com outros programas de inserção socioeconômica e cultural nos assentamentos de baixa renda a fim de amenizar a estigmatização das pessoas em virtude da condição socioeconômica e de sua procedência e condição de moradia.

\section{A Racionalidade do Espaço Urbano Construído}

Sobre a construção histórica do ambiente urbano, podemos dizer que o mesmo está baseado na racionalidade cartesiana, a organização social e espacial das cidades. Porém, temos que analisar os indivíduos que constituem a cidade, além dos resultados de suas relações sociais. Levantada esta questão, entramos na discussão da organicidade e espontaneidade dos laços territoriais criado pelos habitantes do espaço urbano. Ou seja, a organicidade dos gêneros de vida criam um espaço informal, aquém da estrutura pensada e organizada pelos gestores públicos. A confluência entre o espaço formal (espaço planejado) e o espaço informal (espaço oculto) resulta no conflito espacial urbano, isto é, o confronto entre a Cidade Legal, constituída pelos órgãos gestores de regularização e formalização do espaço urbano e a Cidade Real, constituída pelas relações espaço temporais e sociais dos indivíduos que a compõem, como demonstra a figura 1. 
Figura 1: conflito espacial urbano

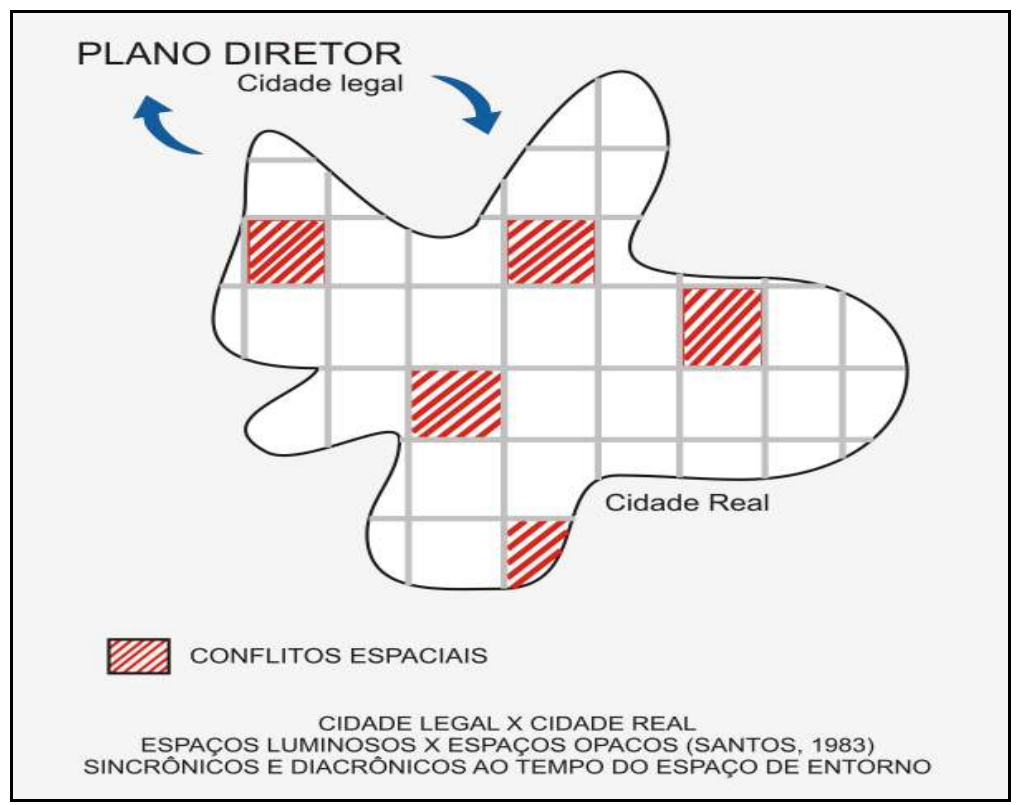

Fonte: PET GEA/UFRGS.

Buscando entender os conflitos espaciais urbanos e a relação entre os habitantes que vivem no espaço formal, de forma sincrônica, que vivem o presente, e os habitantes que vivem no espaço informal, de forma diacrônica, que olham para o futuro; além das políticas públicas existentes no sentido de resolver ou minimizar a pressão sofrida pelo Estado, procuramos a partir da análise do processo de regularização de uma área informal entender os conflitos entre Estado, mercado e sociedade. 
Figura 2: Conjunto Habitacional Princesa Isabel

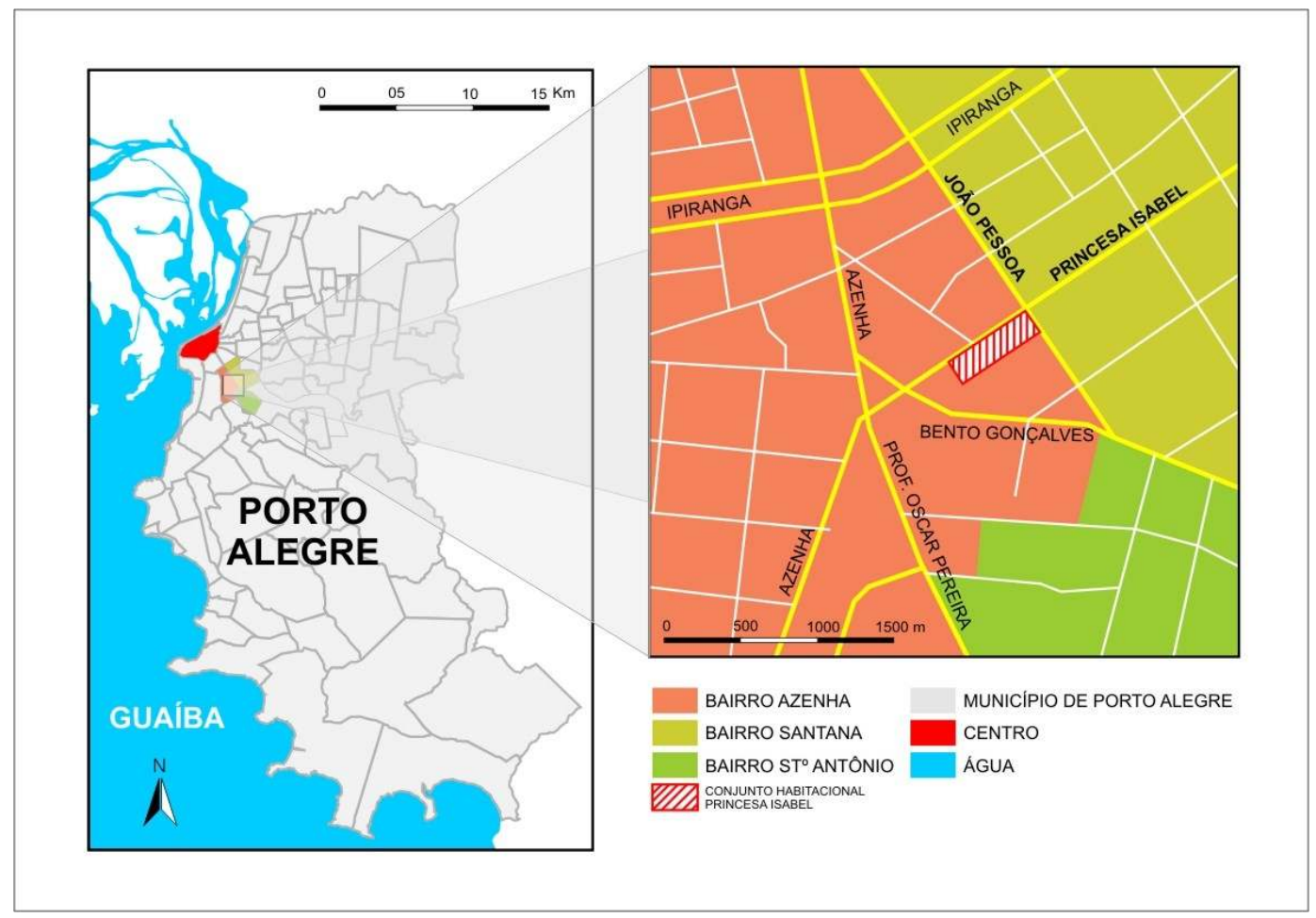

Fonte: PET GEA/UFRGS

O conjunto habitacional Princesa Isabel, como mostra a figura 2, está localizado na esquina das Av. Princesa Isabel e Av. João Pessoa. O mesmo foi fundado em de março de 2005 devendo ser concluído até o final de 2006, com 230 apartamentos residenciais e algumas lojas comerciais. Ali habitarão famílias oriundas do Terminal Azenha e da Vila Freitas de Castro, também localizada no bairro Azenha. Quanto à estrutura, os prédios são compostos de quatro andares possuindo apartamentos de 2 e 3 dormitórios, com áreas de 48 e 55 metros quadrados, respectivamente. As lojas têm 20 metros quadrados e banheiros individuais. Ao se mudarem para o novo local, os moradores assinam contratos de 30 anos de validade, renováveis por mais 30 anos. Quanto às mensalidades, estas variam inicialmente entre R\$ 13,00 e R $\$ 26,00$, possuindo também o compromisso quanto ao pagamento das contas de água e energia elétrica, bem como de responsabilidade sobre o condomínio. A obra esta sendo executada com verbas exclusivas do governo municipal, com um investimento total previsto de R 10 milhões até a conclusão do projeto.

\section{Considerações}

Observamos a efetividade na aplicação do programa de regularização fundiária ao qual foi submetido à área em estudo nesse trabalho. A preocupação do poder público em inserir a 
população reassentada se faz de forma participativa, dando voz àqueles que realmente participam e sofrem com esse processo de raízes tão complexas.

No que concerne à dimensão social do processo de reassentamento de famílias, o projeto está sendo desenvolvido por uma equipe de assistentes sociais contratadas pela empresa licitada para a obra. O projeto social visa à auto-organização da comunidade e tem como planejamento a duração de dois anos. A continuidade desse projeto, segundo as assistentes, depende de parcerias que envolvam o poder público e a iniciativa privada.

A adaptação da população reassentada é extremamente delicada. Afinal, a população está sendo colocada em um espaço totalmente diferente daquele em que construíram toda sua fonte de significado e experiências. Para isso, são desenvolvidas oficinas que visam preparar a população para uma auto-organização. Todas essas oficinas são elaboradas a partir das necessidades e de decisões da comunidade. Basicamente, elas se dividem em três áreas:

- Educação Ambiental;

- Ampliação e Geração de Renda;

- Recreação e Lazer.

A efetividade dos resultados desse trabalho de readaptação é de longo prazo e sua continuidade - no que tange ao amparo especializado de assistência social - é de extrema importância. As dificuldades encontradas e os sucessos obtidos no decorrer desse processo são de extrema importância e deverão servir de amparo para futuros reassentamentos.

\section{Referências Bibliografia}

ALFONSIN, Betânia. O significado do Estatuto da Cidade para a Regularização Fundiária no Brasil. In: CARDOSO, A.L. \& QUEIROZ, L. C. de. Reforma urbana e gestão democrática: promessas e desafios do Estatuto da Cidade. Rio de Janeiro: Revan, 2003. p. 93-102

BONIN, Luis Carlos. A regularização fundiária e a democratização do solo urbano. In: PANIZZI, Wrana M.; ROVATI, João. Estudos Urbanos - Porto Alegre e seu planejamento. Porto Alegre: Ed. Universidade Federal do Rio Grande do Sul, 1993. p. 337-342

CALLAI, Helena Copetti. A cidade e a (re)criação da relação homem-natureza. In Ciência e Ambiente: cidades. Ano IV, número 7, julho/dezembro de 1993. Santa Maria: Editora da UFSM, 1993.

CASTELLS, Manuel. O poder da Identidade. 3. ed. São Paulo: Paz e Terra, 2001. 2v.

CLAVAL, Paul. Geografia Cultural. Florianópolis: ed. UFSC, 1999. 
CORRÊA, Roberto L. Região e Organização Espacial. São Paulo: Ática, 1987. $2^{\mathrm{a}}$ ed. O espaço urbano. São Paulo, Ática, 1995.

FREITAS, Cleid Bernadeti Lima. Regularização fundiária e urbanização de favelas: a questão da moradia e da cidadania na Vila Planetário em Porto Alegre. Dissertação de Mestrado, Porto Alegre/RS, 2003.

HARVEY, David. A condição pós-moderna: uma pesquisa sobre as origens da mudança cultural. São Paulo: Loyola, 1999. $8^{\circ}$ ed.

MARTINS, Maria de Fátima Almeida. Espaço e política na realidade dos conjuntos habitacionais; in O espaço no fim do século: a nova raridade. São Paulo: Contexto, 2001.

MORIN, Edgar. Os sete saberes necessários à educação do futuro. Tradução de Catarina Eleonora F. da Silva; revisão técnica de Edgard de Assis Carvalho. São Paulo: Cortez; Brasília, DF: UNESCO; 2002.

PERUZZO, Dilvo. Habitação: controle e espoliação. São Paulo: Cortez, $1984 .$.

SANTOS, Milton. A natureza do espaço: técnica e tempo, razão e emoção. São Paulo: Edusp, 2002. $4^{\circ}$ ed.

$\overline{\text { Nobel, }} 1990$

Milton. Metrópole corporativa fragmentada: o caso de São Paulo. São Paulo:

SOUZA, Marcelo Lopes de. ABC do desenvolvimento urbano. Rio de Janeiro: Bertrand Brasil, 2003

, Marcelo Lopes de. Mudar a cidade: uma introdução crítica ao planejamento e à gestão urbanos. $3^{\mathrm{a}}$ ed. Rio de Janeiro: Bertrand Brasil, 2004

VALLADARES, Licia do Prado. (org.) Habitação em questão. Rio de Janeiro: Zahar Editores 